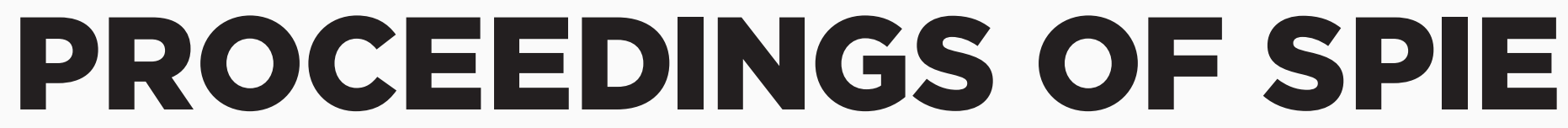

\title{
Training education in enterprise: look for the future
}

\section{Paul Laurin}

Paul Laurin, "Training education in enterprise: look for the future," Proc. SPIE 3831, Sixth International Conference on Education and Training in Optics and Photonics, (16 June 2000); doi: 10.1117/12.388728

Event: Education and Training in Optics and Photonics (ETOP'99), 1999, Cancun, Mexico 
Invited Paper

\title{
TRAINING EDUCATION IN ENTERPRISE: LOOK FOR THE FUTURE
}

\author{
Paul Laurin \\ Instituto de Ciencias de la Educación \\ Universidad Autónoma del Estado de Morelos \\ Département des sciences de l'éducation \\ Université du Québec a Trois-Rivieres
}

\begin{abstract}
The education received at preparatory school or university is insufficient to cover a career of around thirty years. The purpose of this presentation is to point out some fundamental aspects of continuous education. We will describe here the main tendencies of continuous education at the present timeline enterprise. Two main currents support these trends: highefficiency organization and intelligent organization. These trends will allow orientation towards a new form of continuous education that describes the new role of the educator.
\end{abstract}

Keywords: continuous education, in training service, training trends, role of trainer.

\section{INTRODUCTION}

For the past several years public and private organizations have had to deal with a new vocabulary, including terms such as: overall quality, reengineering and work reorganization. The intention of these organizations is to maximize the efficiency of the company as a whole. The efficiency of company personnel is the main clue to the organization's success. As the President-founder of IBM, Watson, used to say when asked what would happen if the organization were totally destroyed: "Give me the same staff and I will build an even a greater organization."

The education received for three or four years at preparatory school or University is insufficient to cover a career of around thirty years. It has to be constantly renewed and adapted to the evolution of society. Education should be ongoing.

The purpose of this presentation is to point out some fundamental aspects of continuous education. The main tendencies of continuous will be described. Two main currents support these trends: high performance organization and learning organization. These trends will allow orientation towards a new form of continuous education. The training practices of an enterprise will be presented

\subsection{Continuous education}

The UNESCO stated that continuous education encourages activities that permit individuals to develop their knowledge and capabilities throughout their lives, thus bettering their living conditions.

Continuous education for personnel also provides for a series of actions and activities in which participants are committed to keeping themselves updated, to enriching their competitiveness, and to bettering their individual and group practices in order to contribute to achieving the goals of their organization 


\section{IMPORTANT TRENDS}

The trends of continuous education in companies have formed the subject matter of intensive study. Considerable changes are predicted in this area. These changes query even the goals, the role of the teachers and the training strategy of continuous education.

According to Spikes ${ }^{1}$, there are seven emerging tendencies on continuous education being offered in companies:

1. - A commitment to growth is anticipated, together with continuous education. Personnel will be taken into increasing consideration as an essential element of company competitiveness.

2. - Customer service will become an increasingly competitive tool for companies. As the competitiveness increases, this will become more difficult to distinguish at product-quality level.

3. - Technological changes will have a great impact in continuous education. In order to face this reality, more know-how, more skills and a better understanding of these changes are needed.

4. - There will be an important number of technological illiterates due to the increased use of new technology.

5. - Educational programs at a distance will increase. Education at a distance refers to educational programs given by different means in different places.

6. - Organizations will invest a considerable amount of time and money in the training of their executives.

7. - Company educational centers will sell their educational services to other organizations or to the general public.

Bassi, Binson and Cheney ${ }^{2}$ corroborate these important trends. The latter have, in fact, engaged in research based on studies of the subject matter as well as questioning experts on the important trends in continuous education announced for companies over the next few years. They are:

1. -Requirements, as new skills continue to increase in order to respond to the rapid changes in technology.

2. - The demand for continuous education will continue to increase. Education must adapt to fit the increasingly diverse needs of the workers.

3. - Company reorganization will continue to evolve in a complex working atmosphere. Organizations can no longer provide a stable atmosphere for continuous education.

4. - The number of people working at the heart of a company educational service will drop significantly.

5. - Technological progress will revolutionize the methods of spreading continuous education.

Face-to-face educational sessions will continue to be the most usual, while modern technology will take a more important role in spreading continuous education. Having the technology in hand will become increasingly evident: educational personnel will be less numerous, transportation and housing costs will decrease.

6. - Instructors will find new ways of delivering continuous education services.

The number of people working in training services will tend to decrease, while the needs for education will increase. With this purpose in mind, the largest American company members of the ASTD (American Society for Training and Development) forum, mention that they currently resort to services outside their organizations for the following needs in connection with continuous education: design and development $(23 \%)$, training $(30 \%)$, administrative support $(7 \%)$ and technical support $(7 \%)$. 
7. - Instructors will previously emphasize the improvement of individual work performance and achievement of the organization's goals. This pattern change will influence the role to be played by educators from now onwards.

. According to Rothwell (1996), two-thirds of the training services provided in large American companies fail to carry out any strict and quantitative study to determine the returns received on the investment in education. Up to what point have skills been transferred to the work itself? Up to what point have individuals and groups improved their performance? Up to what point have the education programs contributed to meeting the goals of the organization?

8. - The overall high performance in work system will expand.

Educational services will be forced to re-examine their role and to place emphasis on results that can be measured.

9. - Institutions will become learning organizations

In learning organizations, instructors are responsible for making learning easy and combining it with the company's goals. It is important for this reason to take the organization as a whole into consideration. It must be ensured that all company systems are prepared in such a way as to motivate, maximize and coordinate learning at all levels of the organization in order for employees to be able to think about what they are learning. The challenge to the instructor will be to put learning organization ideas into practice.

10. - Organizations can emphasize the performance of their employees from the beginning.

It will be inevitable for organizations to update in everyday practice the fact that human beings constitute their greatest wealth.

\subsection{Two main trends.}

The real wealth of a company lies mainly in the capabilities of its personnel. Two trends that are increasingly gaining ground will be progressively introduced in modern organizations that are concerned about the development of their personnel. These trends have considerable influence on personnel training high performance organizations and learning organizations.

\subsubsection{The high performance organization.}

High performance organizations are characterized by:

- Developing the know-how and skills of their personnel that will contribute to company success.

- Making employees capable or influencing the organization as a whole and assuming their responsibilities.

- Providing employees with sufficient power to work towards a continuous improvement in company performance.

- Continuously updating the know-how and skills called for under organizational changes.

Coopers \& Lybrand (1994) have carried out some of the most important research on high performance organizations, as described by Linde, Horney and Koonce ${ }^{3}$. The authors analyzed 300 American and Canadian companies for the purpose of comprehending the impact of continuous education on those employed in high performance organizations. .

The investigation showed those high performance organizations:

- Offer more training to their personnel than traditional organizations,

- Establish a tie between continuous education and company goals.

- Establish a solid comradeship between those responsible for training and the members of the operational units.

- Expect instructors to play the role of a specialist in the apprenticeship as a performance consultant, facilitator, and designer of the teaching.

- Better identify the needs of participants than traditional organizations.

- Question administrators as to their expectations with regard to the training of their personnel. 
- Permanently evaluate the training offered.

- Recognize the strategic value of continuous training.

According to the results of the investigation, high performance organizations offer employees the chance of working closely with their superiors in preparing their training program, in order to ensure that employees develop the skills necessary to achieve company goal. It is clear that training within high performance organizations is far removed from the traditional pattern used in a large number of companies.

\subsubsection{Learning Organizations}

Several researchers have noticed that continuous training should be vastly different today from what it was in the past. It cannot continue to depend on experts who teach participants in the hope that the teachings they provide are sufficient to be introduced in the different media. Neither can one be content with an evaluation, which measures the degree of participants' satisfaction without being preoccupied for transmission of the know-how in daily life. continuous education demands a new model.

Continuous education cannot be limited to a transmission of knowledge, skills and attitudes from top to bottom. It should also provide opportunities so those participants consistently think of what they are doing in order to develop new know-how. Learning organizations add certain characteristics to the new pattern of continuous education.

According to Redding ${ }^{4}$, three premises have been found at the basis of Learning Organizations:

- Organizations and groups learn, not only individuals.

- The level of learning in an organization determines its transformation capacity so that it can face the demands of a fast and fundamental change.

- An organization is a learning organization if its objectives rest on its capacity to learn all the following aspects in a systematic manner: vision, strategies, leadership, cultural action, structure, systems and processes.

The learning organization is an ideal. One cannot ask if a certain organization is a learning organization. One should ask, rather, up to what point such an organization has the characteristics of a learning organization. Organizations must discover their own solutions.

Certain basic orientations, according to Sparks and $\mathrm{Hirsh}^{5}$, are characteristic of continuous education in a learning organization.

1. - From personal development to personal and organizational development.

. It becomes increasingly evident in our time that the success of continuous education depends, at the same time, both on the continuous learning of individuals and an improvement in the capacity of the organization.

2. - Educational activities that have no connecting link with those prepared under a coherent strategic plan for each of the administrative units.

Some training activities are often isolated as regards others, being unconnected to previous activities and without being necessarily followed by others in the future. At times the innovations put forward in connection with these activities do not have the necessary support for implementation. Training activities may, therefore, be nothing more than an eternal new beginning.

3. - Training addressed to the organization as a whole and training of the administrative units in order for these to achieve their goals. 
In learning organizations, each unit will develop an ambitious strategic plan to provide common lines of action to the system as a whole. Each administrative unit will also prepare a training plan so as to contribute, in turn, to the goals of the organization and also to achieve its own goals

4. - From identifying the needs of participants to their identification within a larger context.

Organizations frequently analyze continuous education needs, based on a document distributed to participants. In this way the participants place their expectations on record, together with the training activities they would like to receive. Instructors are frequently unsure, when the time comes, as how to interpret the breakdown of needs completed by the participants .In learning organizations, instructors take into consideration what they perceive as regards the needs of the participants in a larger context. It's means that the needs identified by the participants are submitted in connection with the mission and the objectives of the organization.

5. - From the transmission of know-how and skills by "experts" to collective learning.

Activities in connection with continuous education are traditionally presented as follows: Instructors do research on a given theme and deliver it to the participants in the form of educational activities. Participants receive this training and try to apply it to their environment.

In learning organizations, participants must increasingly commit themselves to the learning process. They meet regularly in small teams in order to exchange points of view about a common subject in order to better their work. For that matter, they will discuss the possibility of transmitting the theme into their daily activities

6. - On educational activities taking place far from the concerns of work, to education in connection with the problems found at work.

Training provided to large groups in which participants are the passive recipients of the advice of an "expert" have, in actual fact, resulted in little change (Sparks and Hirsh, 1997). During training sessions, lecturers frequently imagine that participants are ready to go in to action.

In learning organizations, learning is connected with the everyday problems confronting the participants. It thus appears that the most significant training is that occurring in response to the everyday challenges confronting participants, which is followed by immediate application thanks to experimentation and adaptation to the work (Sparks and Hirsh, 1997).

7. - From training personnel that playing the part of instructor to that offering the services of a consultant on planning, support and information.

The main role of training teams is to provide educational sessions to participants. It is guaranteed that participants will have an excellent instructor and that they will be satisfied.

Educational personnel are asked to play a new role in learning organizations. Besides delivering a high quality education, they help the different work groups to solve problems.

8. - From the responsibility of the training personnel to a responsibility extended to all those forming part of the system.

In the past, the employees of an organization tended to ask the training personnel to plan coordinate and present different training activities. Training was considered as something outside the organization.

In learning organizations, the idea of continuous training is similar to the work to be done, and inspires the different participants in the system to play a new part in training. They become educators and consider the development of each team member as one of their important responsibilities.

9. - From training the main executives of an organization to training all participants in the system. 
In learning organizations, training is offered to all the personnel. In the past, the personnel forming the majority of a company's employees received more relative attention to training. Supporting personnel and professionals rarely took part in training, but also contribute to the goals and objectives of the organization, taken as a whole.

10. - On training from the viewpoint of an apprenticeship which can easily be curtailed to an essential service during budgetary restrictions, without which organizations cannot hope to achieve their goals.

Training activities in the past were frequently considered as something apart. In learning organizations the ambitious goals of a company cannot be achieved without an excellent training program. Training, therefore, continues to form the center of allorganizational reforms and strategies.

These different changes in the field of continuous education are important. They are essential for the creation of a learning organization in which all the participants are, at the same time, students and trainers. These changes represent the most important strategies for achieving the company's objectives. 


\section{TOWARD A NEW KIND OF CONTINUOUS EDUCATION}

These new trends toward training can question almost all company training services. These services behave as though their reason for being is to organize training activities, seminars and meetings. They depend on these activities to prove to management that they are essential to the life of the organization ${ }^{6}$. They claim that what they teach has a positive influence in the work to be carried out by the participants. In organizations handling this traditional model, training services frequently have goals that are different to those of the organization.

Figure 1

The characteristics of the old and new models of continuous education

\section{Old model}

The training activity has a beginning and an end.

During training, different solutions to to different problems are put forward.

Training is set apart from organizational objectives.

The system is blamed if there are no changes after training.

Training offers short-term solutions.
New model

Reflections on activities take place before, during and after training.

There are no quick solutions problems. Rather, they call for a detailed analysis.

Training is directly connected with the organization's goals.

The entire personnel are responsible for the system in which they work.

One must have a long-term vision to contribute significant results.

Adapted from S.J. GILL," Shifting Glass for High Performance," Training and Development, May, pp. 23-31,1995.

Figure 1 shows the main features of the old model as compared to the new. This new inspired model of Gill ${ }^{7}$ rests on four main principles in connection with continuous education:

1. To link the activities of continuous education to the strategic goals of the organization.

2. To maintain a constant focus on the participant as regards the design, development and organization of all continuous education activities.

3. To systematically manage continuous education, keeping organizational performance in mind.

4. To measure the continuous education process, ensuring that it is continuously improved. 


\section{TEACHERS' NEW ROLE}

In line with this new model, those responsible for training cannot continue to play the part, which corresponded to them previously. They must now adjust their role to the new reality. Gill (1995) described the new role of instructors in learning organizations and in high performance companies, as follows:

1. Continuous education activities and identified results must be related to the goals and objectives of the organization.

- To cover organizational goals and strategies.

- To establish a relationship between the goals of the organization and each of the following fields: know-how, skills, behavior at work, success indicators.

- To prepare pre-training activities, training activities and post-training activities which form part of the key processes of the organization.

- To create a repetitive process for presenting content feedback and correction in order to carry out the training within the anticipated time and produce the changes expected in accordance with the objectives of the organization.

- To emphasize the connection between training activities and the needs of the organization throughout the training process.

- To provide training activities which reinforce long-term apprenticeship on a regular basis.

2. To maintain the participant's concentration by preparing, developing and introducing all training activities.

- To involve everyone interested in comparison in training process apprenticeship.

- To validate, in those interested, an analysis of the needs, training objectives, training development and the link between training and company goals.

- To plan and implement training activities, taking into account the identity and learning methods of the participants to be trained.

- To help participants to learn from their experiences in the work field.

3. To manage training according to a systematic approximation of performance in the organization.

- To assist company personnel to understand the dynamic organization between apprenticeship and the following areas: compensation and incentives, the work to be done, the tools, the technology, the equipment, the supervision and evaluation of the work.

- To make participants aware of the systematic factors which make performance slower or faster.

- To combine training activities with the work processes.

- To motivate collaboration between functional units before, during and after the training activities.

4. To measure the training process for continuous improvement.

- To continually measure the training process and its effect on performance and the organization: to bring collected information once again to the attention of the key executives responsible for decision-making in the organization. 
- To help those adopting the decisions to utilize training data to revise and amend training goals and their processing.

- To teach participants how to evaluate their own apprenticeship and transmission.

- To evaluation all difficulties in applying the training: bring the information once again to those responsible for decision taking.

Universities preoccupying themselves about training must become increasingly conscious of the training models produced in the private sector. These could have an important influence on the manner of organizing continuous education.

\section{COMPANY TRAINING PRACTICES}

Some companies offer a continuous education program that fits in with various characteristics of the extensive performance organization and those of the learning organization. Pacific Gas and Electric, the Institute of Canadian Bankers, the Institute for Learning of the Bank of Montreal, The McDonald Corporation, American Telegraph and Telephone, Hewlett-Packard and the Motorola Company have certain interesting characteristics

The Motorola Company, for example, has been recognized as a leader in the continuous education field. In 1988 it received the Malcolm Baldridge award, given to organizations throughout the world, which are interested in continuous education ${ }^{8}$. The company calls for a minimum of 40 hours of training a year, in connection with the work of each of its employees.

Motorola University, founded in 1981, is intended as a change catalyst and a support of continuous improvement of company goals. It offers its services to Motorola organizations throughout the world. It assists the Motorola organizations to build a culture of quality. It has known how to develop academic corporations with educational institutions worldwide.

Motorola University is a learning organization. It is structured in regions where colleagues work. The University manages 7 teaching centers throughout the world and 200 offices in 13 countries on five continents. There are 400 professionals and 700 writers, translators and instructors who provide different services.

In Motorola, training takes the role of an agent for change. It is the role of Motorola University to understand, design and develop training sessions in order to achieve the company's goals. Motorola University tries to maintain a balance between the need of the participants and the training needs at longer term necessary for the success of the organization. In order to take the environment and culture of each center into account, the experts who prepare the training activities work closely with those in change of the administrative units, for the purpose of identifying the results to be achieved through the training activities.

Motorola University offers numerous services to its employees taken as a whole: learning services, made-to-measure services, advisory services, services in conjunction with the community and publication services.

\section{KEY ELEMENTS OF CONTINUOUS EDUCATION}

These trends of continuous education in enterprise place emphasis on individuals as the main performers in contributing to the scope of theirs organizational goals. They put an accent on the improvement of individual, team and organization itself. The following diagram presents in synthesis certain important features of continuous education in high performance organizations. It describes the role of the instructors and different persons taking part in continuous education. In summary, it sheds light on the goals to be attained from continuous education. 
In this new orientation, the educator must be preoccupied not only by the development of the individual, but also by the development of the organization. The continuous education must be in relation with the vision, the mission and the objectives of the organization. The trainer supports the plan of the organization. A real partnership exists between the educator and the administrators of the organization. The planning of the activities is elaborated in conjunction with that taking part in the development of continuous education: the employees, the organization and the trainer.

A true discussion takes place to get a consensus of role of the educator. He works closely with the responsible of the organizational units in order to introduce major changes in processes and culture of the organization. Then the educator not only is a specialist of the content, but also he is preoccupied by the learning of the participants, and by the design of the curriculum. One of his objectives is to develop the skills and the competence of the participants to do a better job. The educator in enterprise is responsible to transmitting new skills to work. In others words, it's a question of transfer of learning in the organization.

With this new orientation, the educator do not play the role of the expert who determines that a specific course should be offered to the employees and taking the necessary action to do so. Here, there is little collaboration with the person in charge of the administrative unit to decide if the course is really necessary. The educator plays a role of collaboration. He maintains contacts with the responsible in the organization, before, during, and after the activities of training. Before the training, he collaborates to analyse performance and to identify the differences between present and that is required to fill company needs. After the activities, he participate to know the effects of the of training on individual performance. He is a performance consultant. He helps the responsible to take actions to improve individual and team performance, and organization efficiency.

This model permits to know new problems, to understand and to confront the reality, to elaborate new problematics for research and to find new knowledges. This model develops a link between theory and practice, between research and action.

Figure 2

Overview of continuous education: key elements

Characteristics

- Personal and organizational development.

- Close links between continuous education and the goals of the organization.

- A coherent plan between those responsible for training and members of the organizational units.

Role of the instructors

- To be a learning specialist, a teacher a program designer.

- To permanently evaluate the training offered; reaction, learning, and behavior results.

- To do all possible to improve employees' performance

\section{Role of the participants}

- To commit themselves to the learning process.

- To participate (employers, employees) in he identification of needs To take care of transmission.

- To achieve the goals of the organization

\section{Goals}

To ensure the transfer of learning.

To maintain organizational change.

To improve the performance of:

The individual

The team

The organization. 


\section{CONCLUSION}

This presentation has shed light on the major trends of continuous education, taking into special consideration high performance organizations and learning organizations. A certain number of key elements of continuous education found in the more dynamic organizations can be found on examining these trends.

The University represents for the society a large group of competencies and experts, which must contribute, to the development of the knowledge. But the professors and the researchers who participate to training of employees in enterprise must maintain a critic distance in front of the training personal in the organization. They must play a collaboration role from the beginning to the end of the training. It's the golden rule to obtain the transfer of the training in the organization This innovative training model in enterprise rest from the beginning on a training philosophy and a process. It is a participatory process where the professor and the organization work together to find a solution to the individual and organizational performance. They look for a strategy.

But, does the professor of the University will accept to play this role? It's supposed that the professor knows very well the organization where the training occurs, communicates easily with the administrators of the company, understands the problems of the enterprise, works with the peoples who are interested by the training. It is the challenge for the future.

\section{REFERENCES}

1. W. F. Spikes, Training in the Twenty-First Century: Where Do We go from Here, ERIC ED 328673.

2. L. J. Bassi, G. Binson, S. Cheney, The Top Ten Trend, Training and Development, January, pp.28-42, 1995.

3. K. V. Linde, N. Horney, R. Koonce, Seven Ways to Make your Training Department one of the best, Training and Development, August, pp.20-25, 1997.

4. J. Redding, Hardwiring the Learning Organization, Training and Development, August, pp.61-67, 1997.

5. D. Sparks, S. Hirsh, A new Vision for Staff Development, Association for Supervision and Curriculum development, Alexandria, Virginia, 1997.

6. S.J. GILL, Shifting Glass for High Performance, Training and Development, May, pp. 23-31,1995.

7 Idem.

8 J. W. Flescher, Shifting Glass for High Performance, Training and Development, May, pp. 25-31, 1995. 